\title{
Researches on the ergonomic design of the workplace for the car driver profesion
}

\author{
Olivia Doina Negoita $^{1}$, Oana $\mathrm{Chivu}^{2}$, Claudiu Babis ${ }^{2, *}$, and Alina Gligor $^{3}$ \\ ${ }^{1}$ Faculty of Entrepreneurship, Business Engineering and ManagementDepartment, Politehnica \\ University of Bucharest, 313 Splaiul Independentei 060021, Bucharest, Romania \\ ${ }^{2}$ Welding and Material Technology Department, Politehnica University of Bucharest, 313 Splaiul \\ Independentei 060021, Bucharest, Romania \\ ${ }^{3}$ University „Lucian Blaga” of Sibiu, Faculty of Engineering, 10 Bulevardul Victoriei 550024, Sibiu, \\ Romania
}

\begin{abstract}
Ergonomic design of the workplace is a matter of utmost importance. Ergonomics should consider reducing the high number of accidents as well as the high amounts paid for insurance. In recent years there have been numerous injuries due to cumulative trauma or due to psychological, sociological and ethical factors. Operators often adapt to improper work conditions, but the number of accidents increases and productivity decreases. The driver of the vehicle must be provided with a suitable space and position so that his posture is physiologically comfortable, does not cause excessive fatigue and illness, there is freedom of movement to drive the steering wheel, steering levers and pedals, which must be accessible and placed in such a way that the driver's requirements are minimal and the visibility is ensured. In the paper there will be presented elements for the ergonomic design of the workplace for the motor vehicle occupation and will be taken into account several factors involved among which we mention the correct positioning of the seat adjustment while driving a car, adjusting the backrest and seat, adjusting the lumbar support, adjusting the steering position, adjusting the headrests to ensure that in the event of an accident, the risk of a head injury is very small.
\end{abstract}

\section{Introduction}

Anthropometry is the science that deals with accurately determining human dimensions, according to race, gender or age. Ergonomics is closely related to the knowledge of medicine and psychology and can be defined as the discipline of adapting work to man, with the aim of rationalizing work at work. Technical anthropometry is intended to meet the requirement for people to be able to work on any machine, that is to say, that their dimensions are integrated into the dimensions of the car, giving it a universal operability character and design details to ensure that the machine is adapted to human.

For the design of the driver's seat, a wide variety of parameters must be taken into account to meet the following four criteria $[1,2]$ :

${ }^{*}$ Correspondingauthor:claudiubbs@gmail.com 
-The driver's seat is designed to be able to reach the vehicle's visibility with clear visibility.

-The seat is designed to accommodate the size and shape of the driver.

- For a long time, the driver's seat should provide comfort.

-The seat must protect the driver during an accident or a collision.

The parameters influencing the design of the driver's seat are shown in Figure 1.

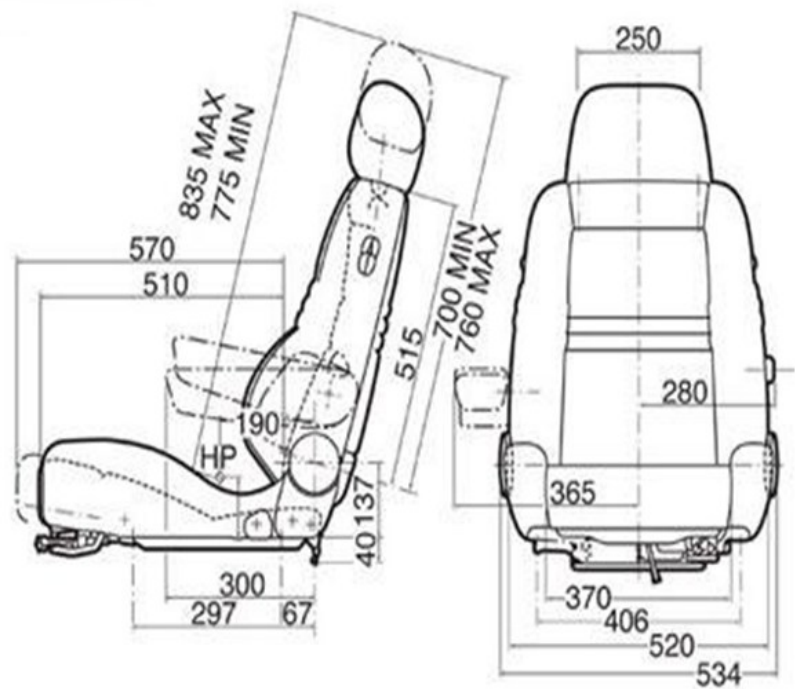

Fig.1. The Dimensional design of the driver's seat

The seat adjustment is entirely dependent on the shape and size of the driver's. Therefore, the chair designer should study the immense amount of anthropometry data before building a prototype. The seat angle is also responsible for the pressure distribution on the seat. The seat backrest can be tilted between the angle 0-100 depending on body shapes and dimensions.

The two extreme positions of the positioning mechanism, with reference to the $\mathrm{H}$ point, are shown in Figure 2.

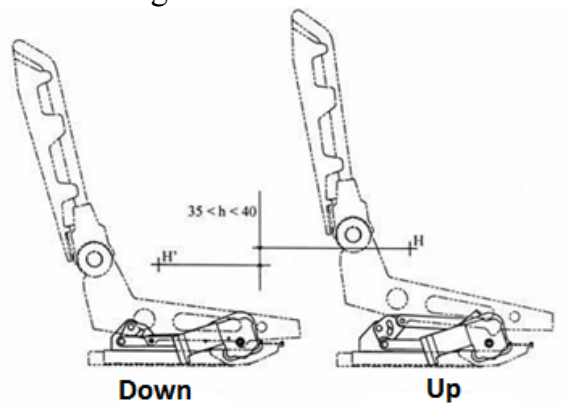

Fig.2. Extreme positions of the seat positioning mechanism

Design data for the seat positioning mechanism are:

- The driver's seat lifting stroke is $38 \mathrm{~mm}$.

- The lifting time of the seat (from the minimum position to the maximum) is about $3,1 \mathrm{~s}$

- The driver's weight and the mechanism is $120 \mathrm{Kg}$

- Gravitational acceleration (for the weight of the mechanism is $\mathrm{g}=9,81 \mathrm{~m} / \mathrm{s} 2$ ).

Considering the movement that the seat will have to perform in the lifting or lowering movement, the most suitable mechanism for making this movement is the articulated quadrilateral. The driver seat positioning mechanism will be composed of a basic 
mechanism (articulated quadrilateral) and a kinematic element, respectively two passive kinematic couplings [3]. The passive kinematic element will be a white seat-seat, it will actually mount the seat, but it will also have the role of reinforcing (increasing stiffness) the mechanism.

\section{Experimental researches}

Experimental research refers to the ergonomics and anthropometry of the workplace for the driver's profession.

Comfort features of vehicles refer to:

-Ergonomically correct positioning of controls, driver and passenger seats, strokes and driving forces of various controls, convenient entry and exit of cars (complying with industry norms and recommendations).

-The vibrations of the car as a whole.

-The vibrations of various car assemblies and parts, the interior noise produced by the car, the temperature, the humidity and the speed of the air in the occupied space of the driver and passengers. Long distance driving can cause lumbar pain [4]. These are determined by the state in the same position in front of the steering wheel for a long periods of time and the vibrations that occur during the running of the vehicle. In order to have a correct steering position we have to start with the following settings, based on the experimental research, as shown in Figure 3:

-Lift the steering wheel and push it as far as possible.

-Leave the chair as far back as possible.

-Leave the post as low as possible.

-Push the seat as far back as possible.

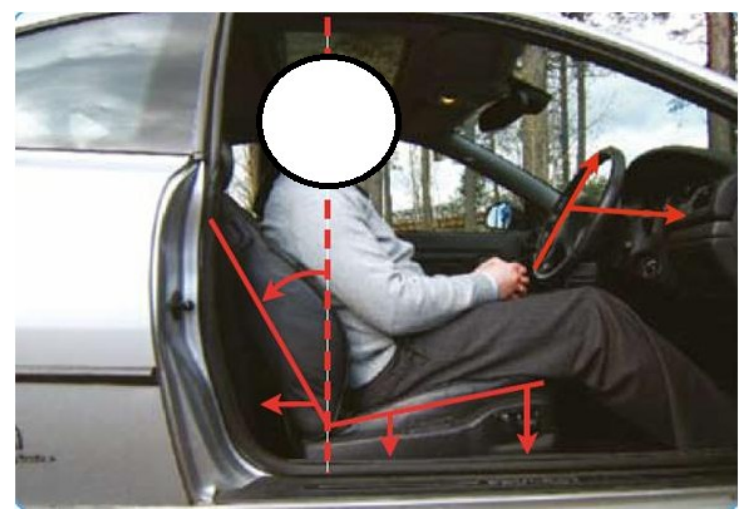

Fig.3. First driver seat settings

Below are presented the phases we need to follow to stay as comfortable as possible in the seat and to reduce as much as possible the negative effects caused by long distance driving.

In the first phase we lift the seat as high as possible to have the best view of the road and a proper space to the roof, as shown in Figure 4. 


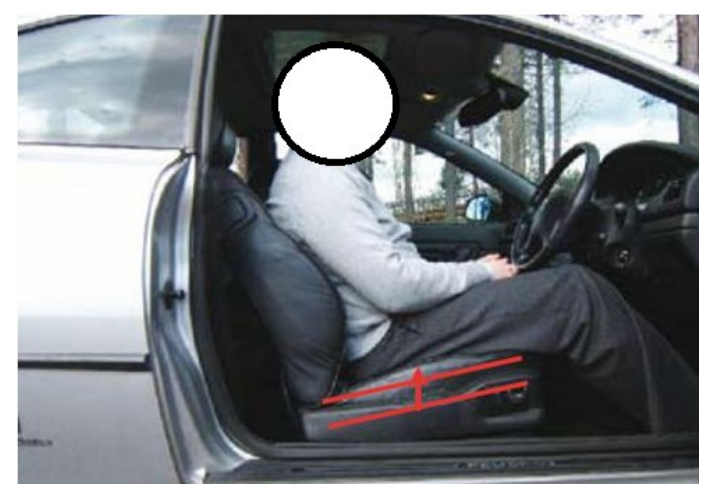

Fig.4. Lifting the driver's seat

In the second phase we move the driver's seat forward until we reach easily the pedals, as shown in Figure 5.

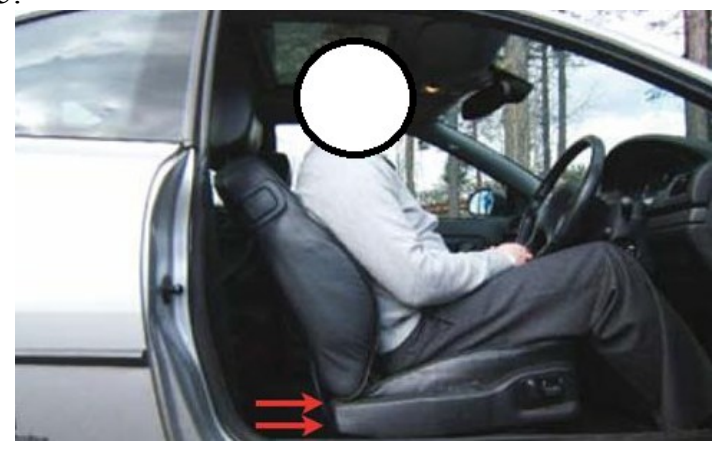

Fig.5. Moving forward of the driver's seat

In the third phase, we adjusted the back of the chair to support the back to the shulders, as shown in Figure 6.

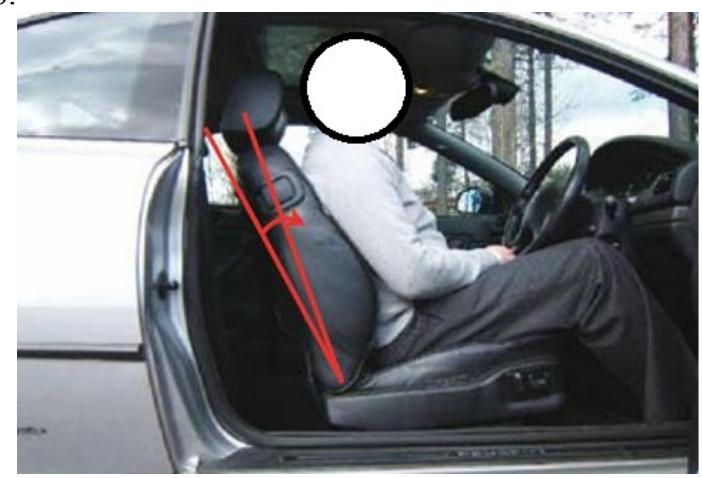

Fig.6. The adjustment of the back of the driver's seat

In phase 4 we adjust the lumbar support to put some pressure on the back of the driver, as shown in Figure 7. 


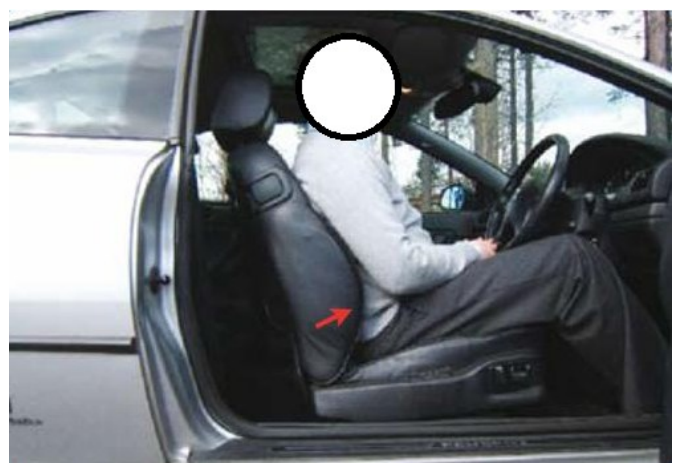

Fig.7. Adjusting the lumbar support of the driver's seat

In the 5th phase we adjust the steering wheel in the back and front and then up and down to be easily maneuvered, as shown in Figure 8.

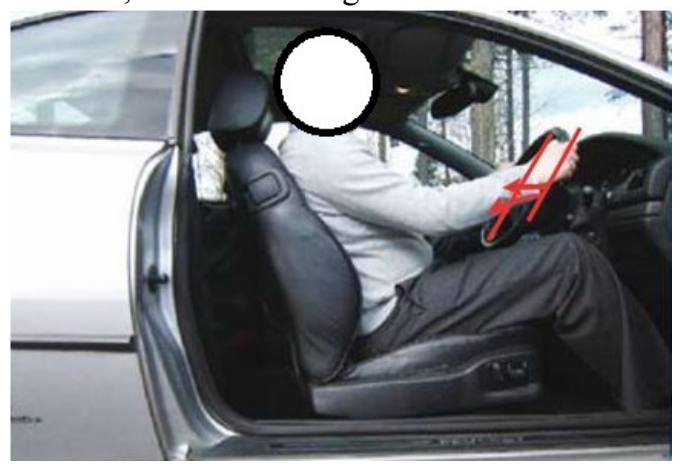

Fig.8. Adjusting the steering wheel

At the last stage we adjust the head restraints to ensure that in the event of an accident the risk of injury is very low, as shown in Figure 9.

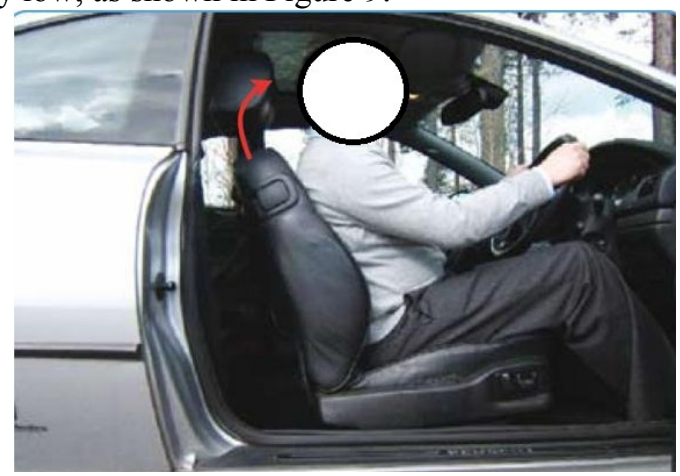

Fig.9. Head restraint adjustment

\section{Experimental results}

In the following are presented experimental results obtained from the research done with the Ramsis software in order to obtain a comfortable position of the driver and the passengers. 
With all the advantages of using computers in ergonomic design, however, the "anthropometric data tables" on the global and partial dimensions of the human body are still used today.

Researchers in the field focus on the size, shape and position of occupants of the vehicle, adults and children, with certain methods that have also been applied in other areas. A major consequence for the anthropometric engineering is caused by the dimensions that affect the body mass, which has led to a detailed investigation of this.

Figure 10 shows a 3D image taken with the Ramsis program of the subjects occupying the driver's space.

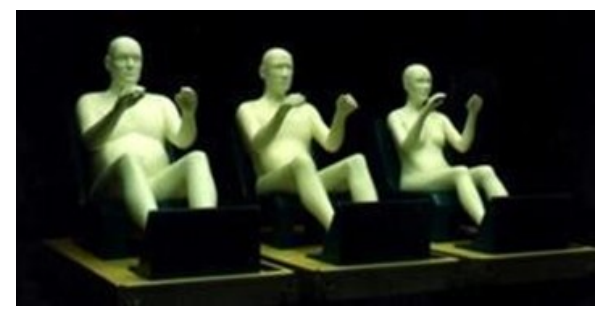

Fig.10. Tridimensional image taken with the Ramsis program

Studies have been done both in the laboratory and in the vehicles. A typical example of a laboratory uses as a study a partial vehicle, often only one place, pedals and steering wheel. An important component of ergonomics in research is the development of positioning models for vehicle occupants.

The aim is to estimate the positions in which people will be able to choose, depending on the occupant's descriptors (gender, stature, weight) and vehicle geometry (steering position, seat height, desired angles, visibility at certain points). The application of these digital models is related to human models, being a three-dimensional image of the human body. The main model uses a series of regression functions, cinematic schemes to predict the posture of the whole body. The advantage of this type of approach is to provide high precision for interior design, usually the balance (increased comfort) and visibility (the ease of observing details from an appropriate position) to model the entire system for the driver's space, whether it is a smaller car, or even a truck cab.

Figure 11 shows some three-dimensional models obtained with the Ramsis program.

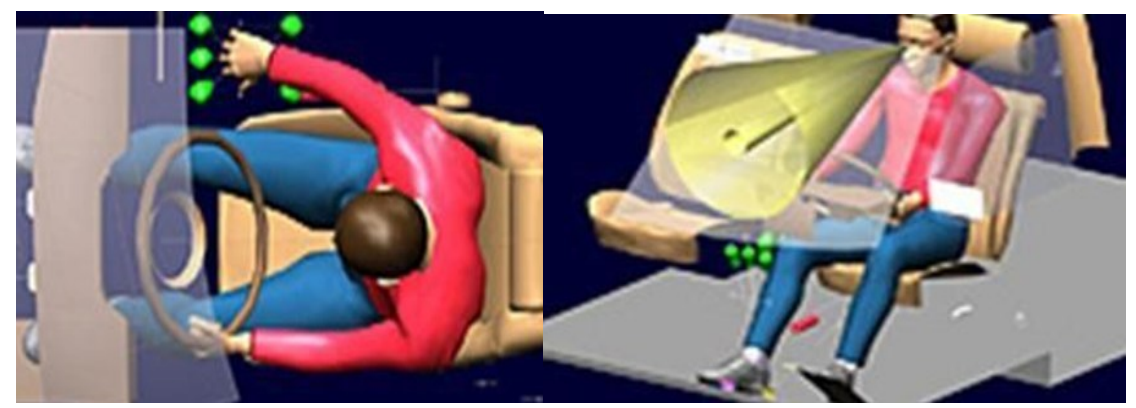

Fig11.The three-dimensional models of occupancy of the cabin, obtained with the Ramsis program

The vertical positioning mechanism is conceived and adaptable to the driver's and passenger's seat, depending on its size, while the dimensions and shape of the driver's and passenger's seats were designed based on experimentals made on a representative sample of people that allowed the ergonomic features presented in the Table 1. 
Table 1. The dimensions and shape of the driver's and passenger's seats.

\begin{tabular}{|l|c|}
\hline \multicolumn{1}{|c|}{ The ergonomic feature } & Range of variation \\
\hline The width of the chest & between 280 și $460 \mathrm{~mm}$ \\
\hline The height of the person's bust & between 800 și $960 \mathrm{~mm}$ \\
\hline The weight of the person & between 47 și $100 \mathrm{~kg}$ \\
\hline & $20^{\circ}<\alpha_{1}<30^{\circ}$ \\
& $95^{\circ}<\alpha_{2}<120^{\circ}$ \\
& $20^{\circ}<\alpha_{3}<135^{\circ}$ \\
The angles for providing a & $86^{\circ}<\alpha_{4}<105^{\circ}$ \\
$0^{\circ}<\alpha_{5}<45^{\circ}$ \\
comfortable position of the person & $80^{\circ}<\alpha_{6}<170^{\circ}$ \\
& $170^{\circ}<\alpha_{7}<190^{\circ}$ \\
\hline
\end{tabular}

The angles whose values were presented in Table 1 and on which depends the correct and confortable driving position are shown in Figure 12

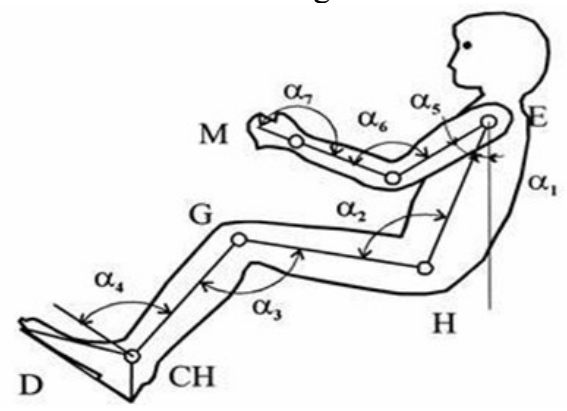

Fig.12. Angles to provide a comfortable driving position

In conclusion, the dimensions of the driving position based on experimental research are presented in Table 2 .

Table 2. The dimensions and shapes of the driver's and passenger's seats.

\begin{tabular}{|c|c|}
\hline Dimensional features & Values \\
\hline The inclined side of the floor to support the foot & should exceed $306 \mathrm{~mm}$ \\
\hline $\begin{array}{l}\text { The distance from the upper edge of the seat cushion to the } \\
\text { floor }\end{array}$ & should not exceed $380-407 \mathrm{~mm}$ \\
\hline Seat positioning & horizontally \\
\hline Horizontal displacement of the seat & $\begin{array}{l}\text { the maximum displacement must } \\
\text { exceed } 100 \mathrm{~mm}\end{array}$ \\
\hline Vertical movement of the seat & $\begin{array}{l}\text { the maximum displacement must } \\
\text { exceed } 80 \mathrm{~mm}\end{array}$ \\
\hline The diameter of the steering wheel & $\begin{array}{l}\text { for heavy vehicles is } 430-600 \mathrm{~mm} \\
\text { for sports and racing cars is } 280-350 \\
\mathrm{~mm} \\
\text { for other types of cars is } 350-420 \mathrm{~mm}\end{array}$ \\
\hline $\begin{array}{l}\text { The angle of inclination of the steering axle to the } \\
\text { horizontal }\end{array}$ & must be between $500-800 \mathrm{~mm}$ \\
\hline $\begin{array}{l}\text { The lateral displacement of the steering wheel (if } \\
\text { necessary) }\end{array}$ & not less than $80 \mathrm{~mm}$. \\
\hline Optimum distance to pedals & $\begin{array}{l}\text { be so that the maximum } \\
\text { recommended pedal stroke does not } \\
\text { touch the floor of the cab }\end{array}$ \\
\hline
\end{tabular}




\section{Conclusions}

The driver of the vehicle must be provided with a suitable space and position so that his posture is physiologically comfortable, does not cause excessive fatigue and illness, there is freedom of movement to drive the steering wheel, steering levers and pedals, which must be accessible and placed in such a way that the driver's effort must be minimal and be assured with an appropriate visibility.

The driver's seat is an inseparable part of any car. Its main function is not only to provide a driver's seat, but also to support, protect and provide a comfortable seat position for the occupants. Today, the design of the driver's seat is of particular importance because the poorly designed seat severely affects human health and the driver's psychological state and thus increases the chances of accidents.

\section{References}

1. A. Gusset, V. de Labonnefon, M. Blancheton, Transportation Research Procedia, Ergonomics and visibility in tramway driving cab, 14, 585-594 (2016)

2. G. M.Sammonds, M.F.Neilm, J .Mansfield, Applied Ergonomics, Effect of long term driving on driver discomfort and its relationship with seat fidgets and movements, 58, 119-127 (2017)

3. I.Kamp, Applied Ergonomics, The influence of car-seat design on its character experience, 43, 329-335 (2012)

4. R.Zenk, M.Franz, H.Bubb, P.Vink, Applied Ergonomics, Spine loading in automotive seating, 43, 290-295 (2012) 